\title{
Obdurate pains, transient intensities: affect and the chronically pained body
}

\section{David Bissell}

School of Environment and Technology, University of Brighton, Cockcroft Building, Lewes Road, Brighton BN2 4GJ, England; e-mail: d.j.bissell@ brighton.ac.uk

Received 16 November 2007; in revised form 21 February 2008; published online 13 February 2009

\begin{abstract}
In contrast to other discourse-centric explorations, I rethink the embodied experience of chronic pain through an affective ontology. Drawing on intensity, as a way of coming to know the qualitative experiential dimension of affect as diminished or heightened, I explore some of the complex relationships between intensity, desirability, and intentionality that cohere around pained bodies. In contrast to transient pain, chronic pain is presented as an undesirable affective intensity that has no recourse to intentionality and meaning but territorialises the body in ways that prevent other intensities from taking hold. Through an encounter with a pain-management programme, I explore a number of strategies for deterritorialising the chronically pained body in order to open it up to more desirable intensities. I argue that ultimately it is the progressive vulnerability and openness that deterritorialisation promises that is the key to becoming otherwise.
\end{abstract}

\section{Introduction}

This pain is an immensely powerful and undesirable beast that has the capacity to tear. This pain, both physical and emotional, is nonrepresentational in the sense that it stubbornly refuses to be represented discursively. It is pure, prepersonal, intensified sensation that eludes and escapes the confines of language. Pain defies order, structure, and definition. There are no boundaries, just joined intensities: different and often ungraspable points of connection and cluster. This pain is obdurate, fixed, and immobile: territorialising the body over and over, and satisfied with its resting place. Since the pain came from nowhere, unwilled and unintentional, there are no trajectories to map and no chain of events to interrogate. With no cause, no explanation, and certainly no invitation, it just began. And yet through these prepersonal fields of force that descended is folded a personal narrative, since this pain happened to my body. It interrupted $m y$ life as I woke on the morning of 3 June 1996, crushing down on the vertex of my head and has yet to withdraw. It is $m y$ chronic headache and demands my attention.

I attempt, in part, to attend to this pain not as an exercise in cathartic testimony, since the implication of my chronic pain is certainly not intended to be some badge of honour. Rather, I attempt to grapple with some of the theoretical problematics that this pain has assembled around me. Chronic pain is not modest. Yet, I attempt to draw on my experience in a way that eschews nauseating sentimentalism. In doing so, I might just help to extend the understanding of the embodied subject and its relationships with the world of phenomena and sense. Drawing on some of the recent insights provided by nonrepresentational theories, together with the body of work that has explored the undesirability of chronic pain (see Honkasalo, 1998), this understanding of pain is inspired by poststructuralist ontologies of affect and the subjectobject dilution that it promises. Specifically, I examine how affective ways of thinking through corporeal experience can potentially assist in understanding what pain does 
to bodies. ${ }^{(1)}$ Rather than considering pain as a set of discourses, representations, or ideologies that pertain to rein in and erase the lived complexities of pain, affective ways of thinking through pain provide a way of exploring not only how the qualitative, processual, lived experience of pain is unstable and uncertain, but also how pain has the capacity to enhance or deplete life. As such, I explore how affective intensity can be an effective way of thinking through the relationship between the body and pain: particularly since the relational qualities of intensity prompt us to consider these augmentations and diminutions of experience. In doing so, I help to illuminate how intensities flow through, cohere around, and act on bodies in all their vulnerability and susceptibility. I therefore prompt us to consider what intensity is and how we might be able to think through intensity relative to other modalities and logics that are used to retrospectively narrate and assemble corporeal experience.

Thinking through pain from the perspective of intensity forces us to consider the relationship between intensity and intentionality, and, with this, the extent to which bodies have the capacity to engineer these intensities. As such, I consider how an understanding of the complexities of intensity offers an insight into the processes at work in the management and alleviation of chronic pain. Connecting the prepersonal with the personal, as I do in this paper, the insights offered by nonrepresentational theories that are explored below have helped me to better comprehend and come to terms with the complex sets of phenomena and sensations that make up my chronic pain.

In the second section of this paper I untangle the prepersonal, theoretical, underpinnings of this paper by describing how the relationship between intensity and lived corporeal experience can help us to understand how affective relations enhance or deplete life. In doing so I draw attention to the complexities of intensity: specifically, the relationships between intensity, desirability, and intentionality. The implications of these complexities in understanding bodily pain through an affective ontology are worked through in section 3. Here, the relationship between intensity, desirability, and intentionality is explored in relation to two broad types of pain. Whilst transient pain often has recourse to intentionality and certain forms of desirability, and may be bound up with particular discourses, chronic pain has a different experiential and affective trajectory. Chronic pain is utterly redundant and, in the absence of meaning and signification, negates intentionality. This pain closes down the body's capacity to affect and be affected. In response to these undesirable intensities of chronic pain, in section $4 \mathrm{I}$ explore how and the extent to which more desirable intensities can be brought about by practices and dispositions that capitalise on these complexities between the intentional and unintentional. The three strategies of pacing, shaping,

(1) Rather than focusing on the affectivity of such intensities, many research projects have tended to follow overtly economic agendas such as the effect of chronic pain on the economy through medical costs and time spent off work. This is perhaps not surprising, since a recent survey by the British Pain Society (2005) revealed that close to ten million Britons suffer pain almost daily resulting in a major impact on their quality of life. A similar survey illuminated that $19 \%$ of adult Europeans experience chronic pain of moderate to severe intensity which seriously affects the quality of their social and working lives (Breivik et al, 2006). When added to the number of people actually affected by those living with chronic pain such as family, friends, and colleagues, such figures demonstrate the magnitude of chronic pain as a serious personal, social, and economic problem. It is a costly and disabling affliction and one of the most common rationales for seeking medical attention. Whilst inevitably receiving much attention in the pages of medical journals, owing to its prevalence it is perhaps surprising that social scientific approaches to researching the effects of chronic pain have been more rather limited (although see Honkasalo, 1998; 2000). Whilst these are important considerations, these aggregate studies have tended to neglect the lived and embodied reality of being with chronic pain. 
and repositioning that I learnt through a pain-management programme illustrate how the unknowability about what intensities could emerge-and therefore the multiple potentials that coalesce around the pained body - is an essential part of their success in helping the chronically pained body to feel better. In doing so, my experience of a pain-management programme illuminates some of the complexities and nuances that are contained within and emerge through action - where the intensities associated with feeling better rely on the emergence of the unintentional and the unexpected.

I therefore do not aim to present a unified rendering of what a painful subject might be. Rather I explore some of the complex foldings of qualitatively different forms of intensity through the body. Whilst the 'management' of intensities might suggest a reining in and closing down of possibility and a nullifying of affect, through the combination of intentional action and dispositions of openness and susceptibility, the pain-management programme works to open up the chronically pained body to new and exciting avenues for affecting and being affected. Intensities can therefore, to an extent, be made more transient to counter the obduracy of chronic pain.

\section{Complex intensities}

In order to think through the relationship between intensity and lived corporeal experience, it is useful at this stage to clarify the particular ontological praxes from which this engagement emerges. Specifically, I follow some of the recent social scientific approaches to thinking through the relations between bodies and sensation which have taken their inspiration from various ontologies of affect and emotion. More broadly, this could be conceptualised as a fusion of poststructuralist thought with phenomenology. Whilst there is no one definition of affect (see Thrift, 2004), the understanding drawn on here is broadly aligned with how nonrepresentational theory (Thrift, 1996) conceptualises bodies. Instead of being defined in terms of a stable identity or essence, nonrepresentational theory, drawing on Spinoza's metaphysics, invites us to adopt a relational definition of bodies where bodies are understood in terms of their capacities or potential for connection. Affect in this sense therefore emerges as prepersonal capacities for action where bodies and objects are defined by their relational capacities to become rather than a set of essentialised or individualised elements. As opposed to being restricted to particular bodies

"affect is autonomous to the degree to which it escapes confinement in the particular

body whose vitality, or potential for interaction, it is" (Massumi, 2002a, page 35). Affect is therefore a transpersonal sense of life, the "perception of one's own vitality, one's sense of aliveness, of changeability" (page 36). Affects do not emerge from individuals, but rather through

"a processual logic of transitions that take place during spatially and temporally distributed encounters" (Anderson, 2006, page 735).

With this in mind, the logic of affect asks us to disband any prefigured notion of a subject-object distinction and instead prompts us to attend to the translocal movements and circulations of affect. Most importantly, though, particularly for considering embodied intensity, through the various complex and shifting relationalities between things, affect has the potential to enhance or deplete the bodily experience of living space-times.

There are many different ways of thinking through and narrating these affective, transindividual, relations. Many have focused on tracing corporeal expressions of affect as demonstrated through the emergence of particular bodily feelings such as anger (Katz, 2002), shame (Probyn, 2005), boredom (Anderson, 2004), and hypnotic excess (Nealson, 2002). Prepersonal, semiconscious, feelings rather than personalised emotions here can be described as the various involuntary shifting corporeal postures and habits 
of a body. Others have focused on documenting the particular ethics (McCormack, 2003; Popke, 2003) and politics (Connolly, 2002; Ó Tuathail, 2003; Thrift, 2003; 2004) promised through affective thought, since what a body can do is an intrinsically political question related to the capacity of bodies to act and experience. Alternatively, some have focused on the problematics of narrating these movements of affect, through the development of attuned grammars and vocabularies (Anderson, 2006), performative styles of writing (Clough, 2000), and the enactment of diagrammatic presentation styles (Dewsbury, 2003; McCormack, 2002).

Running through each of these affective encounters between the body and particular events is a parallel set of relations with what we might call intensity. Whilst many of these encounters use affect and emotion as vehicles for narration, thinking through intensity as a particular translation of affective relations may help us to attend to experiential and embodied phenomena in a rather different way. To think through the relations of 'intensity' as opposed to 'affect' provides a useful way of interrogating and narrating the experiential and embodied dimensions of affect: where affect enhances or depletes life. For Deleuze (2004), qualitative differences in affect, or differences in kind, can be apprehended on a fluid continuum of intensity. Furthermore, Deleuze (1991a) suggests that it is intensity "that gives all the qualities with which we make experience" (page 92). Similarly, Bergson's (2001) writings on the intensity of conscious states demonstrates this qualitative nature of intensity relative to duration and the capacity of things to differ in intensity. To borrow from Massumi (2002a), we can think of intensity as "the strength or duration of the image's effect" (page 24, my emphasis). It disrupts both linear narrative and qualification and is

"associated with nonlinear processes: resonation and feedback that momentarily suspend the linear progress of the narrative present from past to future" (page 26). Intensity is therefore a fundamental dimension of corporeal experience and tracing through intensity allows us to consider the qualitative and shifting depth of corporeal experience. As Massumi suggests,

"our degree of freedom at any one time corresponds to how much of our 'experiential 'depth' we can access towards a next step - how intensely we are living and moving" (page 215).

In this sense, living intensity is a kind of openness contributing to a heightened sense of belonging. Consequently, intensified affect promotes a stronger sense of embeddedness in a larger field of life.

Since intensity can be both intensified and diminished, it might be useful to consider the qualitative effects of corporeal intensity on a relational, sliding, scale (see Ophir, 2005). To draw on this scalar relationship, many recent social scientific engagements have focused on charting corporeal experiences at the end of this scale where intensity is amplified. Influenced by the phenomenological vitalism of Spinoza, Bergson, Merleau-Ponty, and Deleuze (amongst others), this maximisation of corporeal intensity is taken to be a confirmation of the liveliness of being: an affirmation of life. Indeed Massumi (2002b) comments on how "lived intensity is self-affirming" (page 244, my emphasis). The ethic implicit in such thought therefore invites us to consider how these lived corporeal intensities can be enhanced through their maximisation. Following this, many recent engagements at the intersection of phenomenology and vitalism have focused on charting how particularly 'intense' intensities can be successfully engineered by bodies. Thinking through how affective relations can be amplified, or made more intense, is extremely useful as it helps us to understand and shed light on some of the ways in which particular embodied sensibilities are engineered and take shape. Thrift (2000), for example, discusses the evolution of an increasing range of bodily practices that 
"allow the present to be intensified since they produce both an intensified sense of body movement and, at the same time, focus and enhance that movement" (2000, page 45).

This awareness of corporeality and the reenchantment that it promises (Bennett, 2001) therefore emerges from a more intense degree of involvement in an event: the cultivation of feeling life. Intensities are engineered through the amplification of the kinaesthetic element through activities such as extreme sports (Thrift, 2000). Similar amplifications of intensity at times spark through other movement-based practices such as cycling (Spinney, 2006), walking (Wylie, 2002; 2005), and dancing (McCormack, 2002; 2003; Roth, 1998). Such intensities are intrinsically corporeal in that they are felt through the body and might be validated through corporeal experiences such as the stretching and burning of muscles and quickened pulse. Even when the body is not involved in autoaffective movement, many 'extreme' intensities emerge through events of interruption. These might include anger (Katz, 2002), rage, and shame (Probyn, 2005), and are demonstrative of intensities that function as interruptions to the flow of meaning and experience. These intensities might be no less desirable. Indeed, for some (see Hemmings, 2005), rupture as a corporeal experience actually enhances a transpersonal sense of life where the generation of intensity and excitement through moments of rage and anger call forth a heightened and immersive sense of aliveness.

Many studies inspired by affective and nonrepresentational theorisations of the body are foregrounded on an imperative to enliven accounts of bodily experience. Indeed, this ontological prioritisation of vocabularies of action and activity over inaction is in part influenced by the recent interest in the performative body [see Harrison (2000) and Nash (2000), amongst others], where the empirical lens is attuned to the liveliness, excitement, and animation of matter, or, put simply, the "energetics of life" (Kuppers, 2000, page 135). However, and following others (see Harrison, 2008), it is extremely important to work against the rather caricatured claim that the consequence of affective and nonrepresentational theory is a 'just do it' social science where the restlessness of intensifying comes at the expense of obscuring other less lively corporeal subjectivities. The rather damaging implication of this caricature is that it imposes a Western model of subject individuation where the individuals command control and possess ultimate agency over their corporeal movement. Some of the empirical moments shot through engagements with nonrepresentational theory might initially appear to advocate an ethicopolitical imperative where particularly active or 'intense' intensities are implicitly regarded as an ontological good. However, whilst there are many studies that do look at what are, on the face of it, rather active and sometimes very energetic corporeal practices, the vast majority of such studies serve to explore some of the complexities and nuances that are contained within and emerge from activity. Indeed, the openness to the diversity and unpredictability of subjectivities and practices that characterise such work renders the task of generalisation wholly disingenuous.

As such, whilst many studies that set out to explore the undulating topology of affective relations take particularly active practices as their starting point, others have explored the relationship starting from the perspective of inactivity and withdrawal. Comfort, for example, as a complex affectual sensibility felt through the body, could be conceptualised as a desirable lessening of corporeal intensity (Bissell, 2008). Here, the waning of extreme intensities, that are perhaps more associated with forms of practical activity, might be what makes comfort so pleasurable. Comfort as a less intense affectual intensity therefore does not deplete bodily experience but rather enhances it. Certain experiences of diminished intensity, where the body withdraws from the more energetic intensities of life, might be characterised as less desirable, such as boredom 
(Anderson, 2004), waiting (Bissell, 2007), or lassitude (Harrison, 2008). However, there are also many examples of how other less intense intensities are increasingly valorised in contemporary consumer culture where we are being actively encouraged to quiesce practical activity, do less, and be more still. Indeed some of these less intense embodied states and dispositions associated with particular forms of spirituality have been explored in various interesting ways which demonstrate their centrality in many people's everyday lives (Holloway, 2003; Matless, 1991).

What these studies therefore reveal is a complex set of relationships between intensity and desirability, and intensity and intentionality. Bergson (2001) invites us to attend to these complexities of intensity where corporeal intensities are not reduced to the linearities implied by magnitude. What is so significant about this observation is that high intensities always already contain with them other intensities that are folded through the ongoing processual enactment of what it is to be a body. In order to appreciate the growth or diminution of a particular intensity, the experience of that particular intensity will always occur in relation to the experience of other intensities. Following this, certain intensities might diminish our capacity to experience or even tolerate other intensities. Whilst it is perhaps tempting to conceptualise singular selfsufficient intensities on a sliding scale of differences in quantity, this unhelpfully serves to reduce the depth of actual corporeal experience. Instead, recognising the plurality of intensities allows us to consider how different intensities relate to ongoing bodily experience. Wylie (2005), for example, brilliantly highlights these complexities in his narration of a walk along the South West Coast Path. Here, the relationship between different intensities and desirabilities is unsettled through the unpredictable relationships between memory, anticipation, and fleshy, vulnerable, corporeality. Similarly, considering the plurality of intensities also problematises the relationship between intensity and intentionality. Whilst a body might set out to amplify a specific set of pleasurable intensities by undertaking a particular practice, their emergence is wholly unpredictable as can be demonstrated through McCormack's (2002) work on dance. These examples complement a rich heritage of work across a broader spectrum of social scientific engagements that have, in part, highlighted the capricious relationship between intensity and intentionality. Benjamin, de Certeau, and the Situationist Internationale movement, and, more recently, psychogeographical engagements with the city (Fenton, 2005; Pinder, 2001; 2005), all illuminate experiences where intentional bodily movements are juxtaposed with the emergence of particular unexpected intensities that serve to puncture the flow of everyday experience.

With these complexities in mind, in the following section I explore their implications in thinking through two embodied experiences of pain which elucidate further the relationships between intensity, desirability, and intentionality. Attending to the experience of bodily pain endeavours to enhance our understanding of how exactly different intensities flow through, cohere around, and act on bodies.

\section{Painful intensities}

Contrary to the logic of affect, pain is often regarded to be an intensely personal and internal experience. Whilst my chronic headache has inevitably affected other people, especially my family and friends, $I$ am the body that has been charged with the responsibility of dealing with it and getting to know it. As Melzack and Wall (1996) suggest,

"because pain is a private, personal experience, it is impossible for us to know precisely what someone else's pain feels like" (page 41).

Pain has been written about in a variety of different ways: as an emotion, sensation, and discourse. Indeed, pain as a discourse is at the heart of much social scientific work 
on education, discipline, and regulation (or example, see Foucault, 1991). Whilst the unknowability and problematic implicated in translating the pain of another has been a central concern of some (for example, see Wittgenstein, 2002), the task of narrating pain has often rendered corporeal pain to be something that is experienced on a purely individual and subjective basis. However, following Ahmed (2002), it might be useful to move away from an individualised conception of pain to a conceptualisation whereby the happening of pain can be thought through as an affect rather than an effect. From an affective ontology, pain as a prelinguistic phenomenon is intensity. It is the bringing of the body into direct contact with itself. As Arendt (1998) writes,

"indeed the most intense feeling we know of, intense to the point of blocking out all other experiences [is] the experience of great bodily pain" (page 50).

Pain therefore subverts and obscures representation. As Cosgrove (1999) comments,

"pain seems to escape altogether the bounds of representation: pain is too immediate

to be relegated to a mere signifier" (page 410),

a truly nonrepresentational phenomenon. Therefore thinking through pain as a set of affective and embodied experiences invites us to consider some of these complex relationships between intensity, desirability, and intentionality more closely.

Literature on the relationship between the intensities of pain and desirability has a rich heritage. For some, the intensity of pain could be interpreted as revealing the fullness of life and an increased set of connectivities between body and environment. Indeed as Katz (2004) states, "pain is the true fullness of presence" (page 60). This intensification of presence could be enacted through moments of painful anger or annoyance as qualitative expressions of vitality and connectivity. Indeed, there are many examples where pain is invoked for the pursuit of pleasurable sensations. In discussing the figure of the masochist, Deleuze (1991b) argues how pain and pleasure should more appropriately be regarded as complementary sensations through the process of temporary deferral. This temporal distortion of different types of qualitative intensity is perhaps what Tomkins (2000) is alluding to when he asserts how pain and the experiences of one's own affective responses are enjoyable. Similarly, Massumi (2002a) describes how pain and pleasure are not antithetical, where they are not so much opposites, just qualitative attributes on different axes. Following Deleuze and Spinoza on the differentiation between good and bad affects according to their corporeal becomings, a more positive and desirable intensity such as joy as affirmation might be extremely painful through its assumption of a specific posture towards an event as it intensifies its powers of existence. Drawing on a similar distantiation of pleasure from pain, we could consider the often painful but ultimately rewarding practices that are enacted through the processes of exercise at a gym (Crossley, 2006). Where corporeal pain emerges as a residual effect of a set of physical practices, pain may act as an indicator of physical attunement. In such cases, and through the repetition of particular physical routines, the body develops a finely tuned receptivity to the particular intensities of pain. Drawing on the example of cycling, Spinney (2006) asserts that it is

"the successful control and rationing of pain in achieving a goal which may be viewed as pleasure" (page 727).

Similarly, Crossley (2004) describes how circuit trainers learn how to control the intensity of pain through the practice of pacing. Through other physical pursuits such as walking, the emergence of undesirable painful intensities may be controlled and suppressed through the enlistment of a variety of affordances such as strong walking boots (Michael, 2000). Other forms of walking might, however, require pain as an imperative. For example, a religious pilgrimage on foot might require the endurance of physical pain as a necessary symbolic and meaningful experience (Slavin, 2003). 
Other symbolic referents of corporeal pain might emerge through the enactment of particular forms of heroic masculinity (Edensor, 2000; Spinney, 2006) or the assertion that acting outside one's comfort zone and overcoming the barriers that pain constructs represents the apotheosis of the empowered individual within a Western model of subjectification. In each of these events it is the mortgaging of pleasure through the endurance of corporeal pain that might be deemed as being ultimately pleasurable and rewarding.

However, such understandings of pain are highly specific in that they chart the corporeal experiences of a particular form of pain. There are two interrelated aspects that contribute to this specificity. Firstly, these accounts of pain that draw attention to the positive qualitative experiences of pain understand pain as one particular type of intensity: a relatively predictable autoaffection that has a specific and anticipated trajectory. More specifically, this type of painful affliction could be described as 'transient' pain in that the trajectory is one of heightened painful intensity that over time eventually subsides. Indeed, it is the inevitability and promise of subsidence that perhaps best characterises the corporeal experience of transient pains whereby a gradual diminishing of intensity occurs. The promise here is that the painfulness of pain will eventually invite a different set of affective intensities to take hold through the body. Whilst certain physical and creative corporeal capacities may be temporarily curtailed and quiesced, such sensations are perhaps only perceived as rewarding, satisfying, or pleasurable if there is an end, a threshold where a different sensation takes hold: specifically, one that is less painful. Secondly, these forms of temporary pain have a particular relationship with intentionality woven through their bodily experience. We could consider how corporeal pain resulting from physical exertion is a residual effect of a set of willed practices that are actively and intentionally brought to bear on the body. Indeed, with reference to cycling, Spinney (2006) argues that "pain is part of an array of controlled sensations and practices" (page 727). Even in cases where the pain itself is not actively demanded by the body, as in the event of an accidental injury, for example, the particular trajectory that the pain traces is responded to by the body in particular predictable ways. Whilst Melzack and Wall (1996) remind us that the relationship between the cause of pain and its physical sensation is complex, in this case pain erupts as an involuntary corporeal reaction to tissue damage. In the course of experiencing this pain, a set of corporeal autonomic processes are activated whereby the tissue repairs itself again, resulting in the familiar trajectory of transient pain where the intensity gradually and thankfully subsides. Common to both these experiences of transient pain, and perhaps the key to understanding the predictability, is the folding through of discursive regimes. Where Morris (1991) focuses on cultural construction of pain, Ahmed (2002) reminds us that the bodily experience of pain is folded through memory and past experience. The experience of intentionally induced pain through physical exertion and involuntary pain through injury both activate certain meaning-laden understandings of what transient pain does to bodies. In injury, the meanings that are attributed to pain signals are either associated with the positive processes of healing, or messages demanding a particular medical response. Similarly, the pleasurability of intentionally induced pain is perhaps only achieved with the folding-through of certain sensate discourses associated with the positive and perhaps tangible effects of such pains such as the development of visibly larger muscles (see Richardson, 2004). With prescribed meaning comes a certain amount of control over these intensities. Even in the case of the voluntary submission to inflicted pain of Deleuze's (1991b) masochist, pain is still controlled. Crucially, we only become concerned when this trajectory of transient pain is not as expected. 
During the week of 3 June 1996, the pain that I was experiencing was not a concern. I knew that many people experience headaches from time to time. Unwilled and unannounced they just descend. Mildly annoying, yes, but I had experienced headaches before and assumed that this one would eventually subside. By the end of the second week, the pain was still present, pressing down. Whilst the physical intensity of the pain had not increased, my attentiveness to the pain had. This pain was not as I expected. Since I was not particularly stressed or anxious, and had not sustained any head injury, this pain defied meaning. This pain had a different trajectory of intensity: over the ensuing weeks, months, and, eventually, years, the relationship between intensity, desirability, and intentionality was reconfigured. The intensities of chronic pain arrange the body in less predictable ways. Whilst the experiences of transient pain might be folded through regimes of signification, chronic pain is different in that it effects the annihilation of meaning. Chronic pain is utterly redundant and unproductive in that it has no apparent use to the body and is often not the effect of something. In contrast to transient pain, the body does not effect chronic pain and therefore this form of intensity has no active intentionality. Whilst its physiology is complex,

"chronic pain develops over time and persists long after a physiological cause is assumed to have ceased" (Banks and Mackrodt, 2004, page 3).

It can be a symptom of disease or trauma but, as in my case, it can also exist without the presence of either. Put simply, this pain is the result of the sustained and uncontrolled firing of nerves. Where transient pain is acute, transitory, and fleeting, chronic pain as a corporeal intensity is more obdurate and inert.

Whilst Honkasalo $(1998 ; 2000)$ describes some of the symbolic meanings that individuals might attribute to chronic pain, in the absence of meaning and signification chronic pain brings forth a different set of bodily subjectivities that are not so creative, desirable, or enlivening. Far from active, engaged, and intentional, the intensities of chronic pain are synonymous with decay. Passive and acquiescent subjectivities are fostered through the relentless pressing in of the body into itself. What can a chronically pained body do? The incessant pain may prompt the body to give up on a multitude of different planes socially, emotionally, and physically (see Kamen, 2004; Templeton, 2003). Therefore, far from the creation of new potentialities, the qualitative effect of this intensity experienced by chronically pained bodies closes down possibility, negating the precipitation of other forms of affect. The intensity of chronic pain diminishes the body's ability to deal with other forms of affect. Indeed, through chronic pain, the body cannot tolerate high intensities: there is no becoming left to do. As Chare (2005) notes, "pain becomes you, you fade into the background and the background out of which you originally emerged becomes foreground" (page 137). Similarly, Fournier (2002) argues that

"in pain, the body becomes a colossal mass of flesh that ensnares the self and the world; one becomes at once empty (of a self, of meaning) and an excess (of flesh), nothing but a mass of hurting flesh" (page 63).

Without wound, visual mark, or impression it is pure intensity. This intensity has the capacity to become all consuming, with agency to do things to bodies and perception. Far from pleasurable, and heeding the problematic of narrating the experience of pain (Gustafson, 2006), unlike agentively induced pain it is a wholly unpleasant sensory and emotional experience that has the capacity to reconfigure everyday time-spaces. For the body, rather than being confident in everyday commitments, the monstrous taskscape looms before it. The magnitude of these tasks is suddenly overwhelming and too much to bear. Everyday landscapes are transformed from being manageable to wholly unmanageable and the body's capacity to engage is eroded. This also refigures the spatiality of these landscapes whereby the chronically pained body experiences a 
contraction of space (Honkasalo, 1998). Far from intense intensity-extending relations, the overwhelming intensity and longevity of crushing pain breaks down relations and results in the folding in of the body on itself: a deadening of affective charge. Such an affected body can foster a sense of hopelessness and the withdrawal of any ambition aside the motivation to somehow eradicate the pain. As such, being out of control of the pain might precipitate other undesirable intensities such as intense shame (Honkasalo, 1998). Katz (2004) draws a parallel between dread and suffering, suggesting that embracing pain may invigorate a passion for life. However, to draw on Deleuze and Guattari's (2004) notion of the body without organs, as the confluence of a body with its affects and relations, chronic pain has the capacity to deaden. As Fox (2002) notes,

"this body has been burnt out, there is nothing left ... . This body without organs

rattles like an empty husk" (page 358),

containing only the ailments of pain. As such, the subjectivity of the chronically pained body can become dominated and consumed by pain.

In considering strategies to endure transient pain, Ahmed (2002) states how pain sensations demand us to attend to our embodied experience. Whilst in the case of transient pain we may curl up, making our bodies small, in the case of chronic pain, temporarily reshaping the body, perhaps through curling up, does not alleviate these unpleasant intensities. Instead, the body may be shut down in a way that is more temporally sustained. For the chronically pained body, the relationship to time is renegotiated: future long-term expectations contracted. Similarly, the relationship to others is diminished: the pained body is reluctant to socialise, talk, less able to enjoy life. The intensity and longevity of chronic pain therefore dampen other more enjoyable and pleasurable intensities and serve to stifle creativity. In the next section of this paper I move forward more positively by considering some of the possible ways through which the obduracy of corporeal chronic pain as a particular set of intensities can be broken down and how this closing down of worldly possibility can perhaps be abated. In doing so, I illuminate some of the complexities of the relationship between the obdurate undesirable intensities of chronic pain and other more desirable intensities that might assist in making the chronically pained body feel better.

\section{Engineering intensities}

Whereas transient pains are likely to gradually subside, the undesirable, obdurate, intensities that emerge through chronic pain require attending to in order to bring about relief. In this section of this paper I suggest that to change these intensities and to induce more desirable intensities might, in part, be achieved through a set of embodied practices and dispositions that draw on the complexities that emerge between the intentional and unintentional. Here, it might be useful to draw on Deleuze and Guattari's (1987) term 'deterritorialisation' which in this event describes the process by which the ontological coupling between the body and pain can be undone. Whilst all bodies are 'territorialised' to different degrees by the organising institutions, pedagogies and logics of laws, beliefs, significations, and so on, the 'territorialised' body here principally describes the molecular occupation of the body by chronic pain and all the myriad connections that link the body with pain but, crucially, at the exclusion of other connectivities and becomings. Therefore, only through this undoing of the connectivities between body and pain can more desirable intensities emerge. In this section I consider how pain-management programmes can serve to aid this deterritorialisation of the body. Through corporeal deterritorialisation, the body is not consumed by the painful intensities as the pain becomes decentred. The territorial coupling between pain and the body becomes fragmented (Guattari, 1995). Whilst the term 'deterritorialisation' is not part of the pain-management programme lexicon, 
it is extremely useful in helping us to consider how the intensities of pain might not necessarily be eliminated, but rather become refigured in relation to the body.

Before outlining these strategies of deterritorialisation, it is useful to note that, traditionally, deterritorialisation has relied heavily on two particular events. However, and importantly, these strategies that promise to deterritorialise the body in pain might actually serve to enact the converse. Firstly, the overreliance on pain-relieving medication, particularly narcotics, can not only induce some undesirable side effects, but in many cases few are actually capable of affecting the intensity of chronic pain. Overmedication through the false promises of large drug companies (Law, 2006) serves to further ossify the body and reduces the capacity to affect and be affected. Through the ingestion of a range of painkilling drugs, rather than reducing the intensity of the pain, intensities of everyday life are dulled further. As Deleuze and Guattari (1987) suggest,

"instead of making a body without organs sufficiently rich or full for the passage of intensities, [drugs] erect a vitrified or emptied body, or a cancerous one: the causal line, creative line, or line of flight immediately turns into a line of death and abolition .... Black holes and lines of death" (page 285).

The multiple effects of the intensity of the pain and the dulling of medication can effectively zombify the body, rendering it inert and unstable. Secondly, the discomfort of intense pain often prompts regular visits to the doctor's surgery (Kamen, 2004). Whilst the precise rationale of such repeat visits varies, motivation often resides in seeking some degree of reassurance that the pain will eventually cease. Since progress is often minimal, an atmosphere of stagnation condenses. This can not only erode a trusting and beneficial doctor-patient relationship and put a strain on healthcare resources, but the lack of progress from these visits can potentially serve to increase the intensity of the pain. Therefore, these two strategies of deterritorialisation actually serve to further reterritorialise the chronically pained body, strengthening the connections between the body and pain, thereby reducing the capacities to act, affect, and be affected.

Conversely, rehabilitative pain-management programmes are potentially more effective in fostering and circulating forms of affect that serve to deterritorialise the body in pain. So briefly, what is a pain-management programme? In the UK, they are incentives recently spearheaded by both the National Health Service and private trusts to improve the physical, psychological, and social quality, and well-being of people who suffer from long-term chronic pain (Carr and Mann, 2000). They are typically designed for those who have not benefited from conventional pharmaceutical therapies and involve a series of day-long group-based programmes with participants on a weekly basis over a two-month period. They are pedagogical in that patients acquire and develop sets of skills and dispositions to utilise away from the event of the programme. They are primarily cognitive, behavioural, and multidisciplinary and involve specialists from neurology, psychology, and physiotherapy. There are three ways through which pain-management programmes achieve this deterritorialisation: three sets of practices that involve the modification of the relationship between the assemblage which comprises the body and proximate environment which together can be viewed as a continual relational effect. However, what is important about these programmes is the complex relationship between intentionality and unintentionality that they are premised on. Whilst each of these three strategies outlined below involve a degree of intentional, guided, and controlled action, parallel to these the programme also teaches participants to cultivate particular forms of open-mindedness which are less driven by intentionality. This is important since these dispositions are concerned with opening the body up to change by making it more susceptible to the emergence of new and more pleasurable intensities. Indeed, these dispositions of openness could be aligned 
with the extensive heritage of philosophical thinking associated with forms of meditation and, more broadly, theosophy.

The first strategy involves pacing the body and is concerned with altering the speed of the assemblage through the modification of performances and reconfiguration of everyday practices. Rather than continuing to carry out everyday practical tasks in the usual habitual way, pain-management programmes aim to transform the practical and prosaic architecture of everyday life. Participants are taught how, through the logic of breaking tasks up into manageable units and requesting assistance if it is perceived that a certain task might increase painful intensities further, everyday tasks can become more manageable. Whilst activities demanding physical exertion such as housework or exercise may ultimately take longer to achieve, the overall effect is one of reducing the potential for painful flare-ups where the increased intensity of the pain temporarily incapacitates the body. These strategies are designed to enable participants to command a greater degree of control of everyday performances rather than acquiesce to the intensities of pain. The regaining of control over everyday practices that this strategy aims to facilitate reshapes the body and opens up multiple trajectories for becoming rather than the line carved out by the territorialising tendencies of painful intensity (cf Crawford, 2002). Similar to the fine-grained anticipatory work required of an athlete, participants are taught how to monitor and evaluate their activity which involves developing an acute awareness of and an attunement to one's own thresholds where painful intensity is increased above what can be reasonably tolerated by the body. In order to learn these thresholds, a systematic process is developed where the pace of activity for a specific task is at first reduced to a minimum, and is then increased through a gradual process of building-up. The body therefore gains more at the expense of speed through the structured modification of performances (cf Bell and Leong, 1998; Parkins, 2004; Pink, 2007). Through this pacing work, the body must attend to the connections opened up between activity and intensity and in doing so learn how painful intensities can be engineered to prevent them from overwhelming the body. The manipulations of these practices are active and creative interventions that serve to deterritorialise the refrain: the set of habitual expressive behaviours that fashion motivations and thoughts (Seigworth, 2003) that are perhaps sedimented and folded back through the longevity of chronic pain. This strategy promises an interruption to this territorial assemblage whereby the rhythm of everyday life is gradually altered.

The second strategy involves changing the shape of the assemblage through the intentional reconfiguration of bodily materiality. This reshaping involves manipulating direct corporeal sensation through the application of a range of stimuli that are typically temperature or pressure based. This set of strategies firstly involves the enlistment of a range of objects into the assemblage such as Transcutaneous Electrical Nerve Stimulator machines. Such devices stimulate nerves through electrical pulses which are designed to release endorphins to bring about pain relief. Other objects that provide different forms of nerve stimulation at the surface of the body include cooling or heating pads. The enlistment of such objects has the effect of changing the physical properties of the body by introducing and subjecting the body to a range of different sensations as a way to diminish the intensity of the pain. Further, direct physical pressure by other bodies in the form of massage and acupressure is also used to transform and reduce the intensity of the pain. Whilst devices and applications are applied to the body surface, direct physical manipulation assists in developing an attentiveness to the folded materiality of the body. Indeed, whilst many influenced by phenomenology, particularly through Merleau-Ponty (2002), have been interested in developing surficial accounts of the skin as the corporeal surface (see Ahmed and Stacey, 2001; MacCormack, 2006, for example), strategies involving physical corporeal 
manipulation highlight the importance of thinking through corporeal depth. Since the pain itself is nonrepresentational and is not a visible surficial bodily inscription, developing a knowledge of this corporeal depth is often difficult and can take time. This strategy therefore involves learning about and exploring the various interconnected locations of the pain and where within the body pressure provides the most effective pain relief. This can be a difficult task, since chronic pain often resists localisation (Honkasalo, 1998). Importantly, though, it marks a move towards apprehending the haptic as an effective method of engineering and regulating corporeal intensity. Whilst the contact of massage and acupressure is epidermal, it is not just an event that happens on the body surface but involves the movement and stimulation of nerves and muscles through the application of deep pressure. This reconfiguration of the shape of the pained body moves away from the notion of a self-contained body, a

"whole organism comprised and structured out of an intact, logically proportioned set of organs that bind its matter and energy flows neatly with unleaking ends" (Dewsbury, 2000, page 482).

Instead, it marks the connections between bodies that are required to deterritorialise the body in pain, disrupting the notion of a singular body and emphasising the conjoining of skin, pressure, and sensation that enacts the merger of bodies.

The third strategy involves changing the position of the assemblage in order to change the relationship between the chronically pained body and other bodies and objects. This strategy involves refiguring the arrangement between these bodies and objects through the development and cultivation of particular knowledges about and dispositions towards pain. Practically, it involves changing the status of the chronically pained body through a realisation and legitimisation of chronic pain as a disease, a genetic disposition, and a neurological imbalance: in short, a real medical condition. Here I am referring to how, for example, back pain is often maligned by some as being a somehow unreal condition where the chronic pain is downplayed as a residual psychosomatic effect. Therefore, more broadly, this strategy involves altering the bodily perceptions of what constitutes healthy and unhealthy bodies. Rather than a set of discrete practices or activities, this is about the gradual learning of acceptance by chronically pained bodies that pain can be effectively managed. Rather than battling against it (Reynolds, 2007), it involves developing understandings of and alignments with the pain. Whilst not wishing to imply a reduction or reining in of intensity, this strategy involves the systematisation and regulation of the chaotic intensities of chronic pain. This takes place through a rearrangement of what Deleuze and Guattari (1987) writing through Castaneda name as the tonal: the organisation and description of subjectivity. The flip side of this is the nagal which is

"flows of intensity, their fluids, their fibres, their continuums and conjunctions of affects, the wind, fine segmentation, microperceptions [that] have replaced the world of the subject" (page 162).

It might be useful to think of the excessive affective intensity of chronic pain as belonging to the realm of the nagal. The learning of acceptance prevents the annihilation of the tonal that the pressing incipience of chronic pain threatens. This repositioning of what chronic pain is to the body precipitates a reclamation of the tonal and the capacity to "judge, assess and witness" (Crawford, 2002, page 65). This repositioning and acceptance is enacted through both shared encounters at the pain-management programme and everyday interactions with others. This legitimisation empowers bodies by providing them with the right to dictate their interactions with others to a greater degree. Whilst acceptance suggests a form of acquiescence to the pain, it provides chronically pained bodies with strengthened connectivity and an increase in the circulation of desirable intensities. Furthermore, one of the most successful aspects of 
the pain-management programme is how fellow sufferers can share their experiences with others who experience similar pain. Central here is how, through their connectivity, bodies touch each other and how an ethos of responsibility to and caring for others can be fostered. These shared understandings can again facilitate a sense of empowerment: the sociality of pain enacted through the transhuman circulation of positive affects. In this way, repositioning the body becomes an expressive act.

These strategies and dispositions are central to potential deterritorialisation of the body in pain in that they rearrange the mutual entanglement of bodies and objects and provide the possibility for new, more desirable, intensities and lines of flight to emerge. They are pedagogical in that they are sets of practical tools designed to produce and manage a series of affective intensities. They are intended to be gradually learned by bodies through their habitual enactment rather than providing instant pain relief. However, for this reason, participants in these pain-management programmes often find themselves at the mercy of the unruliness of affect and how intensities have the capacity to transcend attempts for their reining in and management. Central to the philosophy of the pain-management programme is an imperative to engineer and circulate amongst and between participants forms of anticipatory hopefulness through these more positive forms of 'being in the world' that aim to deterritorialise the body from pain. Yet, the enactment of practices and cultivation of dispositions by no means determine the form of affective intensities experienced. It is important to recognise that, whilst the three strategies outlined here might at first be suggestive of wholly controlled and intentional actions, the unintentionality precipitated through unknowability is equally central to the processes of deterritorialisation. Whilst participants are taught a set of practices, these are folded through the uncertainty about both the efficacy of the practices and what intensities might emerge. Similar to the dance practices explored by McCormack (2002), or the walking practices narrated by Wylie (2005), the pain-management programme similarly illuminates some of the complexities contained within, and uncertainties that emerge through, practice.

By the end of the two-month course, the wholly undesirable physical sensation of pain experienced both by myself and the other dozen or so participants had arguably not subsided. Indeed, during the intervals between sessions I and many of the other participants often became despondent, questioning the value of the sessions since they were doing very little to reduce the physical sensation of pain. Such experiences demonstrate the fickleness and instability of these affective engineerings which seemed to oscillate between hopefulness and despondency over time, in different spaces and with different people. It became apparent that the primary objective of the programme was not to change the intensity of the pain itself, although as a residual effect of these strategies some pain relief might be brought about. Rather, the programme was a way to change the affective capacities of the body coming to power-and to develop an attunement to intensity through participation. The question therefore changes from the instrumentalist 'did the programme work?' to the performative question 'what did the programme do?' In this vein, the programme was a way of changing habits and perspectives and dispositions of what chronic pain does in relation to the body. The set of strategies taught us to adapt and exploit unused potentialities aimed to foster new relations, to pursue aspirations and open locked doors to new vistas. Central to the programme was a commitment to embrace the unruliness of affective intensity, and therefore the various unintentionalities that emerged as the course progressed, through the process of opening up the body to become more fragile. To counter the obduracy of chronic pain, the strategies of deterritorialisation explored and their enactment through the movement of encounters across the flesh were designed to make the pained body more impressionable and susceptible to positive and desirable intensities such as happiness and joy. 


\section{Conclusion}

Throughout the process of writing this paper I have been anxious, and at times uncertain, about the degree of exposure to give my own pain. Whilst I have been acutely aware that I did not want this account to constitute an exercise in bravado, I was urged on about how my experiences might be well placed to explore some of these ideas that connect the prepersonal with empirically tangible experience. As a way of understanding what is happening to the pained body from an affective perspective, I have demonstrated how thinking through intensity as a qualitative affective charge might be an effective vehicle for coming to understand some of the complexities involved in charting the embodied experience of chronic pain. Where others have focused on narrating some of the various symbolic and discursive interpretations that chronic pain invites (see Honkasalo, 1998; 2000), thinking through chronic pain from the perspective of affective intensity is exciting in that it focuses on how intensities emerge and can potentially be engineered without recourse to the realm of meaning and signification. Whilst personal and societal discourses of pain are inevitably woven through and emergent from the lived experience of chronic pain (Morris, 1991), intensity as prepersonal affect enables us to consider more responsively what chronic pain does to the body.

From this affective ontology, it is possible to evaluate the extent to which intensities can be engineered through particular strategies. Indeed, where other accounts of embodied experiences of pain have tended to focus on the challenges involved in narrating the lived experiences of the pain itself, eschewing the risks of utopianism, I open up a more optimistic avenue by highlighting the emancipatory potentials of intensity to make the pained body feel better through practices that engender corporeal deterritorialisation. Central to this understanding is that, whilst through these practices the change in intensity of the pain itself might be negligible, the ability to manage these intensities is enhanced. These processes of management therefore enhance the body's capacity to induce desirable intensities associated with empowerment and coping. Crucially, such an apprehension reveals the complexities inherent in the qualitative evaluation of intensity in that the physical sensation of pain, in the traditional medical sense, and the affective and emotional sensations of pain cannot and should not be disentangled. Chronic pain as an affective complex is an undesirable intensity that is folded through and saturates the body on a multitude of different planes.

The practices that I learnt at the pain-management programme were designed to break down the corporeal obduracy that chronic pain enacts through a process of opening up the body: a process of exposure. Whilst the process can be difficult, disheartening, even painful, through the gradual accretion of these practices and dispositions into everyday routine the body learns how to become more susceptible to other more positive affective intensities. Ultimately, it is this progressive vulnerability that deterritorialisation promises, the sometimes guilty and often reluctant acceptance and realisation that other ways of being in the world can issue forth that is the key to becoming otherwise. Indeed, the chronic pain-management programme prompted me to consider that which is beyond the dichotomous pain-to-pleasure rhythm: the truly otherwise to the discourse of bodies and desirability. Through its emphasis on changing habit, rather than the incessant prompting of reflective evaluation that pain desires through the yearning to be 'cured', the pain-management programme encourages participants to curtail judgment by making use of the potential that they have. Indeed, this curtailment of judgment or calibration of sensation, reminiscent of Deleuze's notion of counteractualisation, has gradually prompted me to consider my experience of pain as a set of intensities without positive or negative connotations. As such, chronic pain might not be an enemy to be overcome, where life can only begin once its intensity has 
waned, but just an encounter with force. This imperative is not aligned with the rather nauseating ideal of 'always looking on the bright side', but rather promises that bodies are always more than just one particular set of intensities. My body will always be more than pain and the pain-management programme taught me that my body should never be reduced to the obdurate intensities of a chronic headache.

Acknowledgements. Continued thanks to Anne, Jenny, Paul, Val, and everyone at the Newcastle upon Tyne National Health Service Primary Care Trust Pain Management Programme for their commitment, help, and support. Thanks also to the staff in Media and Culture at the University of New South Wales, Sydney for giving me the opportunity to develop these ideas. This paper has benefitted enormously from the extremely generous and perceptive comments made by the three referees. Many thanks also to J-D Dewsbury, Paul Harrison, and Andrew Murphy for valuable comments on earlier drafts and to Peter Thomas for making me finally do something about my pain.

\section{References}

Ahmed S, 2002, "The contingency of pain" Parallax 8 17-34

Ahmed S, Stacey J (Eds), 2002 Thinking Through the Skin (Routledge, London)

Anderson B, 2004, "Time-stilled space-slowed: how boredom matters" Geoforum 35 739-754

Anderson B, 2006, "Becoming and being hopeful: towards a theory of affect" Environment and Planning D: Society and Space $\mathbf{2 4} 733$ - 752

Arendt H, 1998 The Human Condition (University of Chicago Press, Chicago, IL)

Banks C, Mackrodt K, 2004 Chronic Pain Management (Whurr Publishers, London)

Bell M, Leong S, 1998 Slowspace (Monacelli Press, New York)

Bennett J, 2001 The Enchantment of Modern Life: Attachments, Crossings, and Ethics (Princeton University Press, Princeton, NJ)

Bergson H, 2001 Time and Free Will: An Essay on the Immediate Data of Consciousness (Dover, New York)

Bissell D, 2007, "Animating suspension: waiting for mobilities" Mobilities 2 277-298

Bissell D, 2008, "Comfortable bodies: sedentary affects" Environment and Planning A 401697 - 1712

Breivik H, Collett B, Ventafridda V, Cohen R, Gallacher D, 2006, "Survey of chronic pain in Europe: prevalence, impact on daily life, and treatment" European Journal of Pain 10287 - 333

British Pain Society, 2005, "GfK NOP Pain Survey”, http://www.britishpainsociety.org/ full_report.pdf

Carr E, Mann E, 2000 Pain: Creative Approaches to Effective Management (Palgrave Macmillan, Basingstoke, Hants)

Chare N, 2005, "Regarding the pain: noise in the art of Francis Bacon" Angelaki $10133-143$

Clough P, 2000 Autoaffection: Unconscious Thought in the Age of Teletechnology (University of Minnesota Press, Minneapolis, MN)

Connolly W, 2002 Neuropolitics: Thinking, Culture, Speed (University of Minnesota Press, Minneapolis, $\mathrm{MN}$ )

Cosgrove P, 1999, "Edmund Burke, Gilles Deleuze, and the subversive masochism of the image" English Literary History $66405-437$

Crawford J S, 2002, "Michaux's insomnia: the plenitude of the void" Parallax 8 59-77

Crossley N, 2004, "The circuit trainer's habitus: reflexive body techniques and the sociality of the workout" Body and Society $1037-69$

Crossley N, 2006, "In the gym: motives, meaning and moral careers" Body and Society 12 23-50

Deleuze G, 1991a Bergsonism (Zone Books, New York)

Deleuze G, 1991b Masochism: Coldness and Cruelty (Zone Books, New York)

Deleuze G, 2004 Difference and Repetition (Continuum, London)

Deleuze G, Guattari F, 1987 A Thousand Plateaus: Capitalism and Schizophrenia (Athlone Press, London)

Deleuze G, Guattari F, 2004 Anti-Oedipus (Continuum, London)

Dewsbury J-D, 2000, "Performativity and the event: enacting a philosophy of difference" Environment and Planning D: Society and Space 18473 - 496

Dewsbury J-D, 2003, "Witnessing space: 'knowledge without contemplation'” Environment and Planning A 351907 - 1932

Edensor T, 2000, "Walking in the British countryside: reflexivity, embodied practices and ways to escape" Body and Society $681-106$ 
Fenton J, 2005, "Space, chance, time: walking backwards through the hours on the left and right banks of Paris" Cultural Geographies $12412-428$

Foucault M, 1991 Discipline and Punish: The Birth of the Prison (Penguin, London)

Fournier V, 2002, "Fleshing out gender: crafting gender identity on women's bodies" Body and Society $855-77$

Fox N, 2002, "Refracting 'health': Deleuze, Guattari and body-self” Health 6347 - 363

Guattari F, 1995 Chaosmosis: An Ethicoaesthetic Paradigm (Indiana University Press, Bloomington, IN)

Gustafson D, 2006, "Categorizing pain", in Pain: New Essays on Its Nature and the Methodology of Its Study Ed. M Aydede (MIT Press, Cambridge, MA) pp 219-423

Harrison P, 2000, "Making sense: embodiment and the sensibilities of the everyday" Environment and Planning D: Society and Space $18497-517$

Harrison P, 2008, "Corporeal remains: vulnerability, proximity, and living on after the end of the world" Environment and Planning A $\mathbf{4 0} 423-445$

Hemmings C, 2005, "Invoking affect: cultural theory and the ontological turn" Cultural Studies $19548-567$

Holloway J, 2003, "Make-believe: spiritual practice, embodiment, and sacred space" Environment and Planning A 351961 - 1974

Honkasalo M-L, 1998, "Space and embodied experience: rethinking the body in pain" Body and Society $435-57$

Honkasalo M-L, 2000, "Chronic pain as a posture towards the world" Scandinavian Journal of Psychology 41 197-208

Kamen P, 2004 All in My Head: An Epic Quest to Cure an Unrelenting, Totally Unreasonable, and only Slightly Enlightening Headache (Da Capo Press, Cambridge, MA)

Katz J, 2002 How Emotions Work (University of Chicago Press, Chicago, IL)

Katz J D, 2004, "Pain does not suffer misprision: an inquiry into the presence and absence that is pain" Medical Humanities $3059-72$

Kuppers P 2000, "Toward the unknown body: stillness, silence, and space in mental health settings" Theatre Topics 10129 - 143

Law J, 2006 Big Pharma: How the World's Biggest Drug Companies Market Illness (Constable and Robinson, London)

McCormack D, 2002, "A paper with an interest in rhythm" Geoforum 33469 - 485

McCormack D, 2003, "An event of geographical ethics in spaces of affect" Transactions of the Institute of British Geographers, New Series $28488-507$

MacCormack P, 2006, "The great ephemeral tattooed skin" Body and Society 12 57-82

Massumi B, 2002a Parables for the Virtual: Movement, Affect, Sensation (Duke University Press, Durham, NC)

Massumi B, 2002b "Navigating movements", in Hope: New Philosophies for Change Ed. M Zournazi (Pluto Press, Annandale, QLD) pp 210-244

Matless D, 1991, "Nature, the modern and the mystic: tales from early twentieth century geography" Transactions of the Institute of British Geographers, New Series 16272 - 286

Melzack R, Wall P, 1996 The Challenge of Pain (Penguin, London)

Merleau-Ponty M, 2002 Phenomenology of Perception (Continuum, London)

Michael M, 2000, "These boots were made for walking ...: mundane technology, the body and human - environment relations" Body and Society 6107 - 126

Morris D, 1991 The Culture of Pain (University of California Press, Berkeley, CA)

Nash C, 2000, "Performativity in practice: some recent work in cultural geography" Progress in Human Geography 24653 - 664

Nealson J T, 2002, "Empire of intensities: a random walk down Las Vegas Boulevard" Parallax $878-91$

Ophir A, 2005 The Order of Evils: Towards an Ontology of Morals (Zone Books, New York)

Ó Tuathail G, 2003, "Just out looking for a fight: American affect and the invasion of Iraq" Antipode $35856-870$

Parkins W, 2004, "Out of time: fast subjects and slow living" Time and Society 13363 - 382

Pinder D, 2001, "Ghostly footsteps: voices, memories and walks in the city" Ecumene 81 - 19

Pinder D, 2005, "Arts of urban exploration" Cultural Geographies 12383 - 411

Pink S, 2007, "Sensing Cittàslow: slow living and the constitution of the sensory city" Senses and Society $259-78$

Popke E J, 2003, "Poststructuralist ethics: subjectivity, responsibility and the space of community" Progress in Human Geography $27298-316$ 
Probyn E, 2005 Blush: Faces of Shame (University of New South Wales Press, Sydney)

Reynolds R, 2007, "The demise of sadness: melancholia, depression and narcissism in late modernity" Australian Humanities Review 41 http://www.lib.latrobe.edu.au/AHR/archive/ Issue-February-2007/Reynolds.html

Richardson N, 2004, "The queer activity of extreme male bodybuilding: gender dissidence, auto-eroticism and hysteria" Social Semiotics 14 49-65

Roth G, 1998 Maps to Ecstasy: A Healing Journey for the Untamed Spirit (New World Library, Novatarro, CA)

Seigworth G, 2003, "Fashioning a stave, or, singing life", in Animations of Deleuze and Guattari Ed. J D Slack (Peter Lang, New York) pp 75-105

Slavin S, 2003, "Spiritual practice: the pilgrimage to Santiago de Compostela" Body and Society $91-18$

Spinney J, 2006, "A place of sense: a kinaesthetic ethnography of cyclists on Mont Ventoux" Environment and Planning D: Society and Space 24 709-732

Templeton G, 2003 The Pain Chronicles: Recollections of a Chronic Pain Sufferer (Cold Tree Press, Nashville, TN)

Thrift N, 1996 Spatial Formations (Sage, London)

Thrift N, 2000, "Still life in the nearly present time: the object of nature" Body and Society $634-57$

Thrift N, 2003, "Bare life", in Cultural Bodies Eds H Thomas, J Ahmed (Blackwell, Oxford) pp $145-169$

Thrift N, 2004, "Intensities of feeling: towards a spatial politics of affect" Geografiska Annaler, Series $B \mathbf{8 6} 57$ - 58

Tomkins S, 2000 Affect Imagery Consciousness: The Positive Affects (Springer, New York)

Wittgenstein L, 2002 Philosophical Investigations (Blackwell, Oxford)

Wylie J, 2002, "An essay on ascending Glastonbury Tor" Geoforum 33441 - 454

Wylie J, 2005, "A single day's walking: narrating self and landscape on the South West Coast Path" Transactions of the Institute of British Geographers, New Series $30234-247$ 
Conditions of use. This article may be downloaded from the E\&P website for personal research by members of subscribing organisations. This PDF may not be placed on any website (or other online distribution system) without permission of the publisher. 